\title{
DTM generation with Radarsat-2 Data without GCP
}

\author{
Th. Toutin and K. Omari \\ Canada Centre for Remote Sensing, Natural Resources Canada \\ 588, Booth Street, Ottawa, Ontario K1A 0Y7 \\ Thierry.toutin@ccrs.nrcan.gc.ca
}

\begin{abstract}
Digital terain models (DTMs) were extracted from high-resolution Radarsat-2 stereo high-resolution images. The metadata supplied by MacDonald, Dettwiler and Associates Ltd. were used to replace the ground control data used to compute for the deterministic geometric model. The DTMs are then evaluated with 0.2-m accurate lidar elevation data. Because DTMs included the height of land covers, elevation linear errors with 68 and 90 percent confidence level (LE68 and LE90) were both computed over the full study site and the bare surfaces. Comparisons were also performed with the same rigorous model using accurate differential GPS as ground control points (GCPs). Using the radargrammetric model using eight dGPS GCPs achieved the best results (3.3 $\mathrm{m}$ LE68) than using only the metadata $(3.9 \mathrm{~m}$ LE68). However, this accuracy is compensated by the fact that the user does not have to collect any ground data, which offers a strong advantage in remote and harsh environments.
\end{abstract}

\section{$1 \quad$ Introduction}

Since Leberl (1978), a large number of researchers around the world have investigated stereo-radargrammetric methods using deterministic modeling and applied to high spatial resolution (HR) of recent spaceborne synthetic aperture radar (SAR) sensors (Toutin, 2011). However, they generally require ground control points (GCPs) to accurately determinate the unknown parameters of radargrammetric models. While the metadata supplied by MacDonald, Dettwiler and Associates Ltd. (MDA) with Radarsat2 data are still limited by the orbit ( $5 \mathrm{~m}$ at $90 \%$ for Radarsat-2) and calibration timing uncertainties (Robertson, personal communications, 2009), they could be used to replace the GCP role for computing the unknown parameters.

The objectives of this research paper are then to apply only these MDA metadata to a radargrammetric model and to evaluate the accuracy of final 3D products. Comparisons when input accurate ground control points (GCPs) to the radargrammetric model are also performed. The radargrammetric model is the deterministic Toutin's model already applied to most of SAR data, including Radarsat-2 (Toutin and Chénier, 2009). The Radarsat-2 stereo data are acquired using its high-resolution (HR) mode with steep and shallow viewing angles over Canadian study sites. 


\section{$2 \quad$ Study site and data set}

\subsection{Study Site}

The study site is located north of Québec City, Québec, Canada $\left(47^{\circ} \mathrm{N}, 71^{\circ} 30^{\prime} \mathrm{W}\right)$ and spans different environments: urban and residential, semi-rural and forested. The elevation ranges almost from $10 \mathrm{~m}$ in the city in the southeast to around $1000 \mathrm{~m}$ in the Canadian Shield in the north. The northern part is a hilly to mountainous topography $\left(5^{\circ}-30^{\circ}\right.$ slopes) mainly covered with forests (deciduous, conifer and mixed) while the south part is a semi-flat topography $\left(0^{\circ}-5^{\circ}\right.$ slopes $)$ with urban and residential areas.

\subsection{Radarsat-2 Stereo Data}

The Radarsat-2 SAR data set (Table 1) included two stereo images (20 by $20 \mathrm{~km}$ ) acquired September 10 and 14, 2008 with the C-band ultra-fine mode (1 by 1 look; 1.62.4 by $3 \mathrm{~m}$ resolution) in VV polarization from descending orbits with view angles of $30.8^{\circ}-32^{\circ}$ (U2, Figure 1) and $47.5^{\circ}-48.3^{\circ}$ (U25, Figure 2) at the near-far edges, respectively. The VV SAR data were processed as single look complex (SLC) product (16 bits) in the slant range geometry and orbit oriented with a pixel spacing of 1.3 by $2.1 \mathrm{~m}$. The metadata were provided in separate files.

Table 1: Description of the two HR SAR data acquired with the C-band VVpolarization ultra-fine mode of Radarsat-2

\begin{tabular}{|c|c|c|c|c|c|c|}
\hline $\begin{array}{c}\text { Mode \& } \\
\text { Beam }\end{array}$ & $\begin{array}{c}\text { Acquisition } \\
\text { date }\end{array}$ & Orbit & $\begin{array}{c}\text { Look } \\
\text { angles }\end{array}$ & $\begin{array}{c}\text { Ground } \\
\text { coverage }\end{array}$ & $\begin{array}{c}\text { Sensor } \\
\text { resolution }\end{array}$ & $\begin{array}{c}\text { Pixel } \\
\text { spacing }\end{array}$ \\
\hline U2 & $2008-09-10$ & Desc. & $30.8^{\circ}-32^{\circ}$ & $20 \times 20 \mathrm{~km}$ & $2.4 \times 3.0 \mathrm{~m}$ & $1.3 \times 2.1 \mathrm{~m}$ \\
\hline $\mathbf{U 2 5}$ & $2008-09-14$ & Desc. & $47.5^{\circ}-48.3^{\circ}$ & $20 \times 20 \mathrm{~km}$ & $1.6 \times 3.0 \mathrm{~m}$ & $1.3 \times 2.1 \mathrm{~m}$ \\
\hline
\end{tabular}




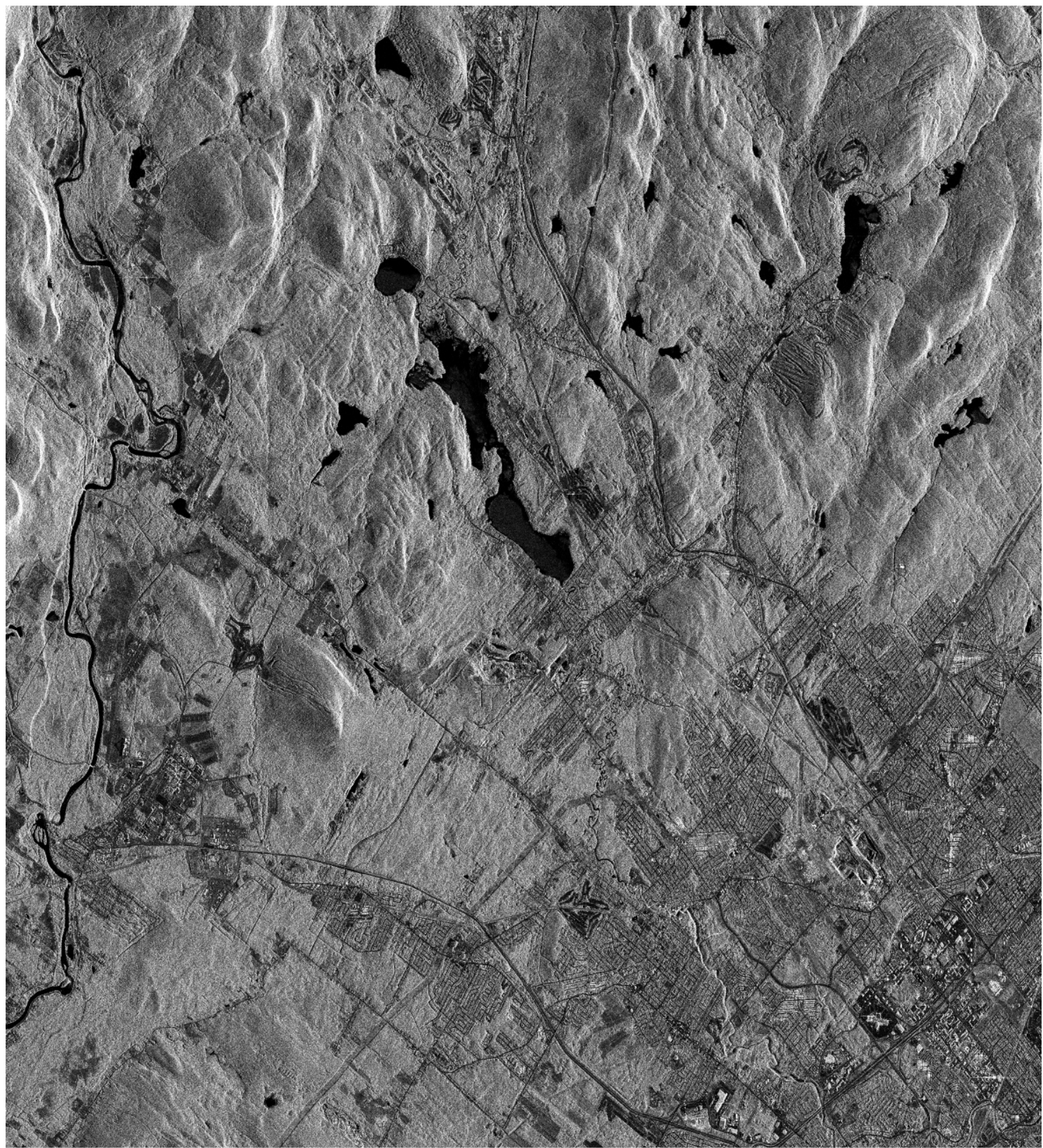

Figure 1. Radarsat-2 U2 image ( 1 by 1 look; around 22 by 26 km; 2.4 by 3 m resolution; view angles of $30.8^{\circ}-32$ ), north of Québec City, Quebec, Canada.

"Radarsat-2 Data (c) MacDonald, Dettwiler and Associates Ltd. (2008) - All Rights Reserved" and Courtesy of Canadian Space Agency. 


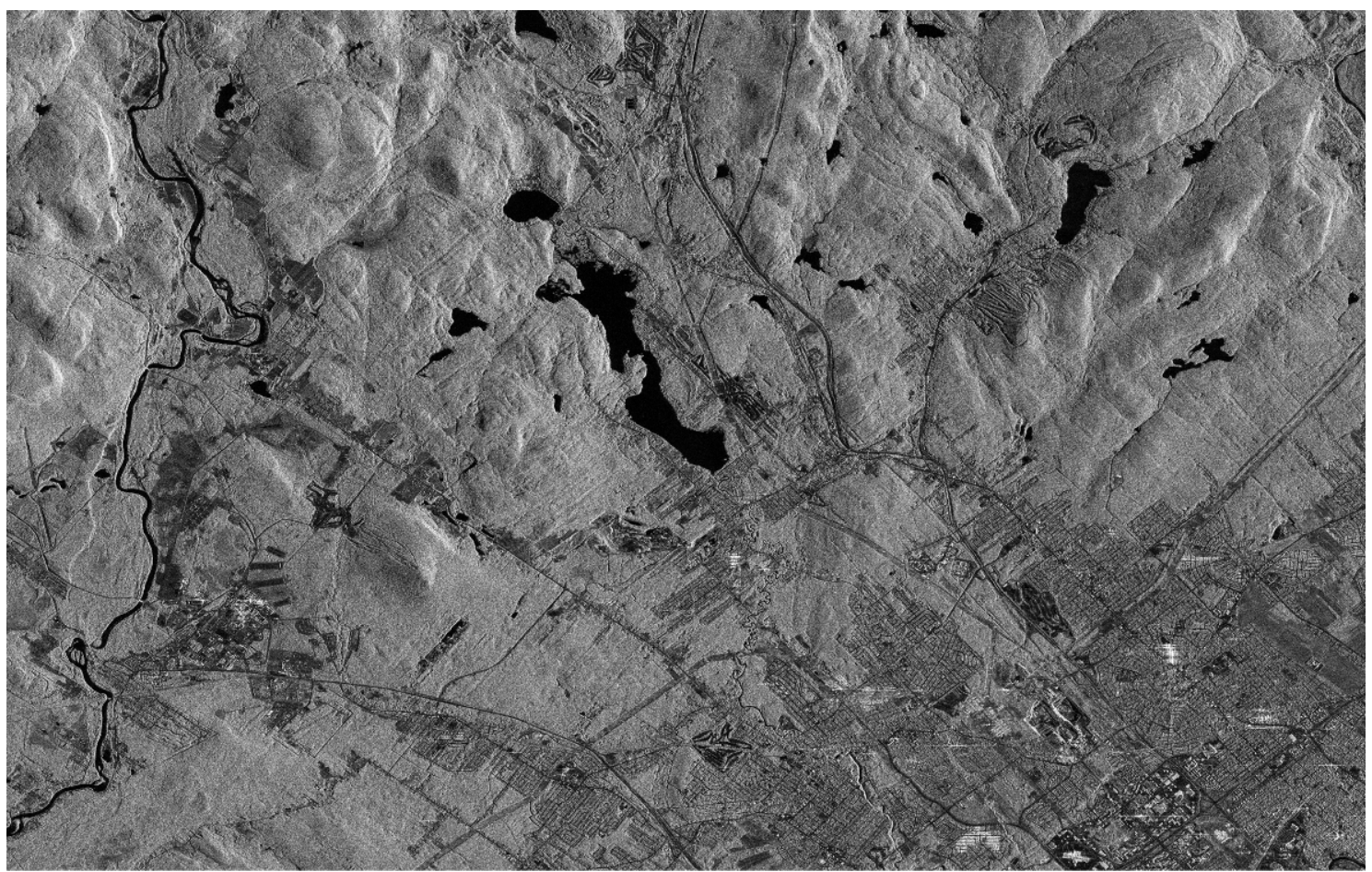

Figure 2. Radarsat-2 U25 image (1 by 1 look; around 22 by 22 km; 1.6 by $3 \mathrm{~m}$ resolution; view angles of $47.5^{\circ}-48.3^{\circ}$ ), north of Québec City, Quebec, Canada.

"Radarsat-2 Data (c) MacDonald, Dettwiler and Associates Ltd. (2008) - All Rights Reserved" and Courtesy of Canadian Space Agency.

\subsection{Cartographic data}

The reference cartographic data included ground points, mainly road intersections and electrical poles, collected from a differential Global Positioning System (dGPS) survey in November 2008 with 3-D ground accuracy of 10-20 cm. The collected points were used either as GCPs to compute the physical/empirical models or generally as independent check points (ICPs) to quantify/validate the model accuracy.

In addition, accurate spot elevation data (first echoed return) were obtained on 06 September 2001 from a lidar survey collected by GPR Consultants (www.lasermap.com) (Fowler, 2001). Ten swaths were acquired covering a $5 \mathrm{~km}$ by 13 $\mathrm{km}$ area, which approximately corresponds to the east part of the stereo images. Since the research objectives were to evaluate stereo-extracted DSMs, the lidar elevation data were not interpolated into a regular-spaced grid to avoid the propagation of interpolation error into the checked elevation and the evaluation.

\section{Description of the method}

The processing steps for DSM generation with HR SAR stereo-images using the deterministic Toutin's model TM were previously addressed and documented for Radarsat-2 (Toutin, 2010). The main processing steps are: 
1. The acquisition of the SLC SAR images and metadata (orbit information and $3^{\text {rd }}$ order RFM coefficients). The SLC data were pre-processed into 16-bit amplitude images, filtered with the enhanced Lee filter (Lee, 1980, Lopes et al., 1990). Metadata were used to determine an approximate value for each parameter of TM.

2. The collection on stereo-images of 60 points from dGPS survey (10-cm accuracy). The main error was due to the image pointing (less than one pixel for electrical poles and 1(-2) pixels for road intersections. The collected points spanned the total volume of the terrain relief to avoid extrapolations, both in planimetry and elevation. They were mainly used as independent check points (ICP) for TM validation.

3. The computation of TM computed with eight and no GCP (TM_8 and TM_0).

4. The elevation extraction used a hierarchical (7 steps) grey-level image matching (mean normalized cross-correlation method with sub-pixel computation of the maximum of the correlation coefficient) applied in the quasi-epipolar geometry (Ostrowski and Cheng, 2000). The quasi-epipolar DTM was then reprojected with 6$\mathrm{m}$ regular grid spacing into the cartographic projection.

The evaluation of the extracted DSMs with the lidar elevation data was finally performed over about 5,500,000 points: mean, linear error with $68 \%$ and $90 \%$ levels of confidence, LE68 and LE90 were computed.

\section{$4 \quad$ Results and discussions}

4.1 Accuracy evaluation of stereo-radargrammetric models

Toutin and Chénier (2009) already demonstrated that TM's precision is around $25 \mathrm{~cm}$ : the model will thus not induce any significant errors in the next evaluation. Table 2 summarizes the results of TM computation for the two tests: the errors (bias and standard deviation, Std in meters) computed on a large number of ICPs (52 or 60) providing independent and unbiased evaluations of the modeling accuracy.

Table 2: Number of ICPs with biases and standard deviations (Std, 1 sigma in metres) for each modeling Test.

\begin{tabular}{|c|c|c|c|}
\hline Test number & $\begin{array}{c}\text { Number of } \\
\text { ICPS }\end{array}$ & $\begin{array}{c}\text { Bias (m) } \\
\mathbf{X}, \mathbf{Y , ~} \mathbf{Z}\end{array}$ & $\begin{array}{c}\text { Std (m) } \\
\mathbf{X}, \mathbf{Y}, \mathbf{Z}\end{array}$ \\
\hline TM_8 & 52 & $1.5,1.7,-0.6$ & $0.85,0.88,2.46$ \\
\hline TM_0 & 60 & $1.8,2.6,-2.7$ & $0.93,1.33,2.34$ \\
\hline
\end{tabular}

The two Tests (TM_8 or TM_0) achieved consistent results. TM_8 also achieved the best Std results being the reference results for TM (Toutin, 2010). These results demonstrate that user-collected GCPs (mainly with dGPS) still perform better than the metadata in the geometric processing, whatever the recent improvements in the nonimaging sensors. On the other hand, the small lost in accuracy for TM_0 is compensated by the gain of processing the stereo-images with no GCP. 
4.2 DSM evaluation results

The second results are qualitative evaluations of quasi-epipolar DSMs generated using TM-8 (Figure 3, top) and TM_0 (Figure 4, bottom).

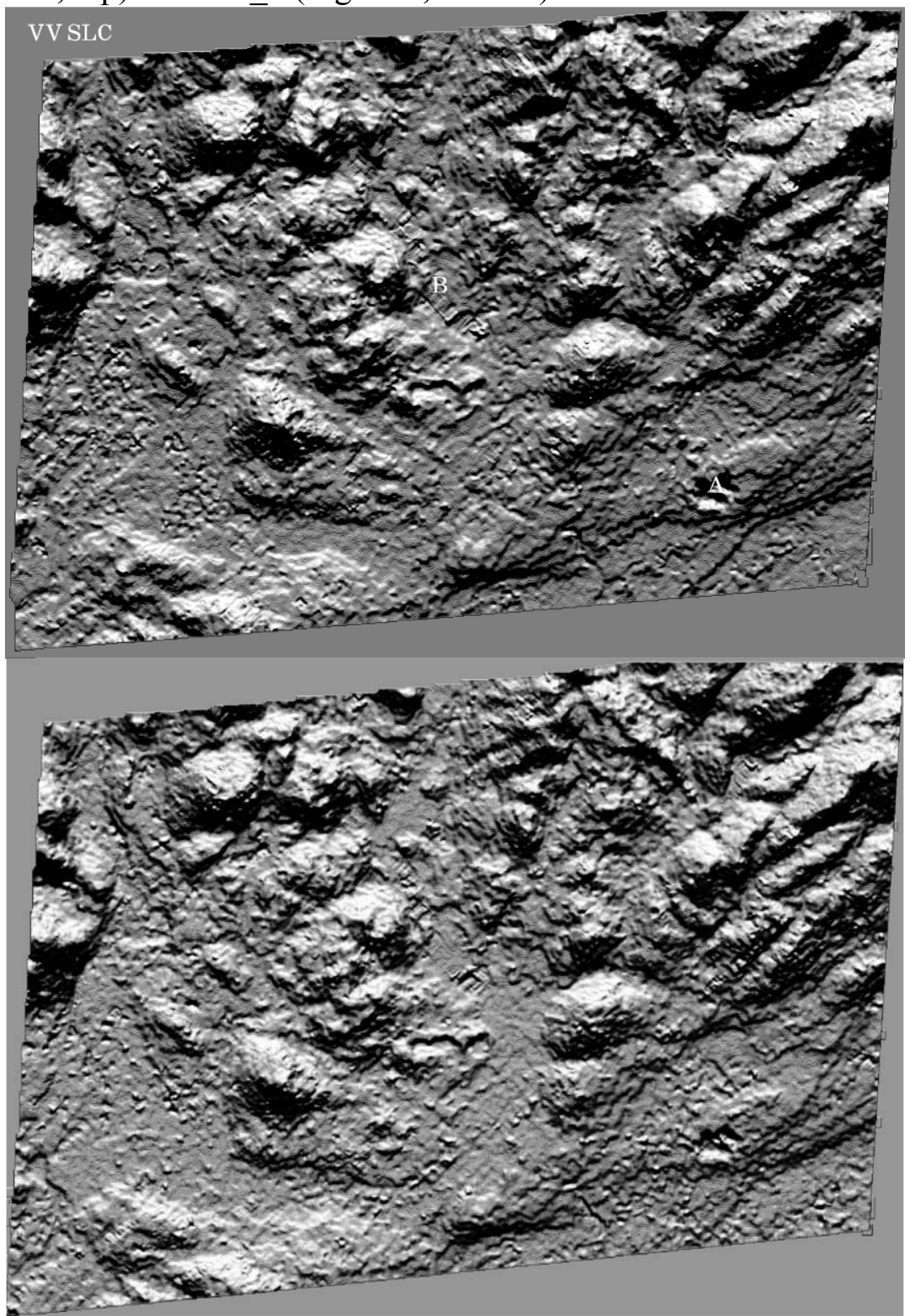

Figure 3. Comparison of North-oriented shaded-relief DSMs (18 by $16 \mathrm{~km}$; 6-m grid spacing) using TM-8 (top) and TM_0 (bottom)

Visually, both DSMs well describe the macro-topography and the macro linear trends with mountains and valleys, enhancing the structural geological framework in the northwest-southeast direction. However, some high-frequency topographic variations are perceptible in TM_8 (Figure 3, top) in the flatter areas. 
The quantitative evaluation was performed over the coverage of the lidar data, being on the half eastern part of DSMs. The computed accuracy would be still representative of the overall DSMs because all relief (flat to mountainous; all slopes and azimuths) and all land covers (urban, semirural, bare soils, and forested areas) of the study site were embraced in this sub-area. Because the C-band SAR phase scattering center typically occurs at $40-60 \%$ of the canopy depending on the SAR resolution and the tree characteristics (deciduous, conifer, mixed, height, density, etc.) (Kenyi et al., 2009), the comparison with lidar elevation data in the vegetated cover can thus generate both systematic and random errors. Consequently, the results computed over the full lidar coverage do not reflect the true DSM accuracy since the dominant source in the error budget is the difference between the compared stereo-SAR and lidar elevation points. not the DSM accuracy. To have the true elevation accuracy, the error evaluation was also performed only on bare surfaces, where the stereo SAR and lidar points were at the same ground elevation. The bare surfaces were also representative of the full terrain relief because they occur not only on low lands and slopes but also in the high lands and slopes (mainly, in the northeast). Consequently, Table 3 give the accuracy results (bias, LE68 and LE90 in meters) computed on bare surfaces for both DSMs.

Table 3: Accuracy results for DSMs computed over the bare surfaces: bias, LE68 and LE90 in metres.

\begin{tabular}{|l|c|c|c|}
\hline DSM & Bias (m) & LE68 (m) & LE90 (m) \\
\hline TM_8 & -2.6 & $\mathbf{3 . 2 9}$ & $\mathbf{6 . 2 5}$ \\
\hline TM_0 & 0.1 & 3.89 & 6.95 \\
\hline
\end{tabular}

The small negative biases are coherent with the modeling results (negative Z-bias over ICPs). It seems normal that the original TM_ 8 consistently achieves the best accuracy versus TM_0: 60 and $70 \mathrm{~cm}$ difference for LE68 and LE90, respectively because the definition, quality and accuracy of dGPS GCPs (10-cm cartographic and sub-pixel pointing accuracy) are better than the metadata accuracy (5 $\mathrm{m}$ at $90 \%)$. TM_8 should thus enable better contour lines to be derived.

\section{CONCLUSIONS}

The objectives of the research were to extract DSMs from Radarsat-2 HR stereo images acquired over a residential/rural hilly area in Quebec, Canada. Taking advantages of the improvements of the metadata the 3D deterministic Toutin's models can then be used without GCPs. In order to verify its adequacy the same processing were performed with 8 GCPs. DSMs were then compared to point-cloud lidar elevation data over bare surfaces only. TM_0 with no GCP achieved slightly worse results than TM_8, both on the stereo-radargrammetric model $(8-48 \mathrm{~cm}$ difference in the three axes) and on DTM (60 and $70 \mathrm{~cm}$ difference for LE68 and LE90, respectively). This reduction of accuracy is, however, compensated by the gain of processing stereo-images and generating DSMs 
with no GCP, which increases the applicability of Radarsat-2 to remote and harsh environments as well as study sites without any cartographic or ground control data.

\section{Acknowledgements}

This work was realized in cooperation with the Centre for Topographic Information in Sherbrooke, Quebec. The author thanks the Canadian Space Agency (CSA) for providing the images under their Science and Operational Applications Research (SOAR) Program. This work was financially supported by CSA under the Government Related Initiative Program.

\section{References}

L.W. Kenyi, R. Dubaya, M. Hofton and M. Schardt, "Comparative analysis of SRTMNED vegetation canopy height to LIDAR-derived vegetation canopy metrics," International Journal of Remote Sensing, vol. 30, no. 11, pp 2797-2811, 2009.

F.W. Leberl, "Satellite radargrammetric," Deutsche Geodactische Kommission, Munich, Germany, Serie C, vol. 239, 156 pages, 1978.

J.-S. Lee, "Digital Image Enhancement and Noise Filtering by Use of Local Statistics," IEEE Trans. Pattern Analysis and Machine Intelligence, vol. 2, no. 2, pp. 165-168, 1980

A. Lopes, R. Touzi and E. Nezry, "Adaptive Speckle Filters and Scene Heterogeneity," IEEE Trans. Geosci. Remote Sens., vol. 28, no. 6, pp. 992-1000, November 1990.

J.A. Ostrowski and P. Cheng, "DEM extraction from stereo SAR satellite imagery," in Proc. IEEE Geosc. Remote Sens., IGARSS 2000, 24-28 July 2000, vol. 5, pp. 2176 2178, doi: 10.1109/IGARSS.2000.858347.

Toutin, Th., Multi-Source Data Fusion with an Integrated and Unified Geometric Modelling, EARSeL Advances in Remote Sensing, 4 (2): 118-129, 1995.

Th. Toutin, 2010, Impact of RADARSAT-2 SAR Ultrafine-Mode Parameters on Stereo-Radargrammetric DEMs, IEEE Trans. Geosc. Remote Sens. Vol. 48, no. 10, pp.3816-3823, October.

Toutin, Th., 2011, "State-of-the-art of geometric correction of remote sensing data: a data fusion perspective", International Journal of Image \& Data Fusion, Vol. 2, No. 1, 3-35, March. 
International Archives of the Photogrammetry, Remote Sensing and Spatial Information Sciences, Volume XXXVIII-4/W19, 2011 ISPRS Hannover 2011 Workshop, 14-17 June 2011, Hannover, Germany

Toutin, Th. and R. Chénier, 2009, 3-D Radargrammetric Modeling of RADARSAT-2 Ultrafine Mode: Preliminary Results of the Geometric Calibration, IEEE-Geoscience and Remote Sensing Letters, 6(2):282-286 \& 6(3):611-615. 